\title{
Prevalence of hamstring tightness and associated factors among sewing machine operators
}

\author{
Game Kankanamage Kanishka ${ }^{1}$, Hansika Sandamali ${ }^{1}$, Isuru Weerasinghe ${ }^{1}$, Lakmali Binduhewa $^{1}$, \\ Chathurangi Dilshara ${ }^{1}$, Chandodini De Silva $^{1}$, Denika Silva ${ }^{1}$, Aindralal Balasuriya ${ }^{2}$ \\ ${ }^{1}$ Faculty of Allied Health Sciences, General Sir John Kotelawala Defence University, Sri Lanka \\ ${ }^{2}$ Faculty of Medicine, General Sir John Kotelawala Defence University, Sri Lanka
}

\section{Article Information \\ Total Number of \\ Words 2160 \\ Tables 3 \\ Figures 3}

Authors have no conflicts of interest to declare

Keywords: Hamstring tightness, prolonged sitting, Sewing machine operators

Date of submission:12.06.2019

Date of acceptance:18.10.2019

Author responsible for correspondence: Game Kankanamge Kanishka

No. 18, Perera Avenue

Kohuwala, Nugegoda

Tel. 0762967966

E mail: bimalkanishka@gmail.com

https://orcid.org/0000-0003-2122-9915

DOI: http://doi.org/10.4038/cjms.v56i1.4957

\begin{abstract}
Background:

Hamstring is a key component of flexibility in the human body and it is more prone to get tightened. Inability to achieve greater than 160 degrees of knee extension when the hip is flexed to 90 degrees is considered as hamstring tightness.
\end{abstract}

\section{Objectives:}

This study aims to find the prevalence of hamstring tightness among sewing machine operators and to assess the association of hamstring tightness with prolonged sitting, body mass index, physical activity level and gender.

\section{Method:}

A descriptive cross sectional study was carried out among 169 sewing machine operators aged between 18-60 years of a selected garment factory. Passive knee extension (PKE) test was used to measure the hamstring tightness among sewing machine operators. A validated interviewer administered questionnaire was used to determine the physical activity level among the participants.

\section{Results:}

Prevalence of hamstring tightness among sewing machine operators is $83.4 \%(\mathrm{n}=141)$ and it is higher in males $(91.8 \%)$ than females $(78.7 \%)$. There was a significant association between prolonged sitting and hamstring tightness in the dominant limb $(\mathrm{p}=0.02$, chi square $=7.79$ ). Significant associations were not found between hamstring tightness with the BMI level $(\mathrm{p}=0.46, \mathrm{r}=-0.05)$ and physical activity $(\mathrm{p}=0.41, \mathrm{r}=-0.06)$.

\section{Conclusion:}

Majority of the sewing machine operators have hamstring tightness. Prolonged sitting is a contributory factor in hamstring muscle tightness.

\section{Background}

Muscle tightness occurs due to the reduced ability of the muscles to deform by reducing the range of motion of the joints they act on. Muscle tightness cause musculoskeletal pain and reduce flexibility[1].

Hamstring is a large muscle group comprised of three muscles; semitendinosus, semimembranosus and biceps femoris which cover the back of the thigh. This muscle group crosses the two joints, hip and knee as it originates from ischial tuberosity and inserts in to the back of the knee (both tibia and fibula). Hamstring functions as knee flexors and hip extensors. Thus it contributes to maintain the flexibility in the human body $[1,2]$.

Hamstring tightness is defined as the inability to achieve more than $160^{\circ}$ of knee extension while 
the hip is flexed at $90^{0}$ [3]. Hamstring tightness can lead to many of the musculoskeletal disorders such as low back pain[2,4,5], hamstring muscle injury, patellofemoral pain and plantar fasciitis[6], Furthermore, severity of mechanical low back pain increases with the increase of hamstring tightness[5].

There are over 300-350 apparel industries in Sri Lanka which provide employment to over 300,000 directly and over 600,000 indirectly. Apparel industry brings the largest export income to the country[7]. Sewing machine operators play a key role in this process, but they experience various discomforts and pain. Female garment workers in Sri Lanka have reported a high incidence in back pain (57.3\%) and knee pain (31.7\%) which interfere with the ability to work while a few have missed their work altogether[8]. In the seated position, hamstring is held at shortened position due to knee flexion and posterior pelvic rotation. In prolonged sitting, this constant shortened position develops hamstring trigger points and cause muscle tightness[2]. Further, seated position increases the pressure on lumbar intervertebral disc. Therefore, prolonged sitting can increase the mechanical stress on lumbar spine[9]. Furthermore, frequent forward bending increase the mechanical stress on the spine with people having hamstring tightness[10]. The above postures are commonly seen among sewing machine operators. Therefore, sewing machine operators can develop low back pain as a result of hamstring tightness. Furthermore hamstring flexibility is influenced by several factors like age, gender, BMI and inadequate physical inactivity[1,11]. Studies have been conducted among different populations such as college students, office workers, physiotherapy undergraduates and athletes but studies are limited among sewing machine operators[12-15]. Therefore, it is important to understand the prevalence of hamstring tightness and possible factors associated with hamstring tightness among sewing machine operators.Aims of this study were to find out the prevalence of hamstring tightness among sewing operators of a garment factory in the Colombo district and to evaluate the association of hamstring tightness with prolonged sitting (more than six hours per day at work), gender, physical activity level (PAL), body mass index (BMI) and dominant leg.

\section{Method}

A descriptive cross sectional study was conducted among 169 sewing machine operators from a purposively selected large scale garment factory in the Colombo district. Ethical approval was obtained from the Ethics Review Committee of the Faculty of Medicine, General Sir John Kotelawala Defence University.

Sewing machine operators aged between 18 - 55 years were selected from the list of workers using the simple random sampling method. The participants with minimum of 6 hours of continuous sitting at work per day for a minimum of 5 days per week and employed at the current position continuously for a minimum time period of 6 months were included in the study. Employees with previous musculoskeletal or neurological conditions associated with the hip, knee or spine, leg length discrepancy, pregnancy and employees who were not physically and psychologically fit at the time of data collection were excluded. To select sewing machine operators to be included in the sample, a table of random numbers was used which included numbers for total number of sewing machine operators in the garment factory. First, a pin is dropped on to the number table and the number closest to the point of the pin is taken as the starting number. This continued on reading the table from left to right to select the participants.

Data collection was done using interviewer administered questionnaires and through physical assessments.

Personal information and working experience data were collected using an interviewer administered questionnaire while Global Physical Activity Level Questionnaire (GPAQ) was used to determine the physical activity level among participants. It is a standard questionnaire which has been developed by World Health Organization (WHO)[16]. The GPAQ showed acceptable evidence of short- and long-term testretest reliability by activity category and modest validity evidence in Southeast Asian countries[17,18]. Metabolic equivalents (MET) minutes per week were calculated using this questionnaire to detect the physical activity levels of the participants. The Questionnaire comprised of 16 questions that capture physical activity undertaken in different behavioral domains; at work, in transport, discretionary (also known as leisure or recreation) and sedentary behavior. Questions in the work and discretionary domains assess the frequency and duration of 2 different categories of activity defined by the energy requirement or intensity (vigorous- or moderateintensity physical activity). In the transport domain, frequency and duration of both walking and cycling for transport is captured, but no 
attempt is made to differentiate between these activities. One additional item is collected; time spent in sedentary activities. Physical activity level was determined by using the analysis guide which is provided by $\mathrm{WHO}[16]$.

Hamstring tightness was measured using the passive knee extension test (Figure 1). It is designed to minimize the associated pelvic motion, to have a fixed end point, to be convenient and quickly performed[19]. The reliability of this method was shown to be high and there is no difference between the tests - retest measures found $(r=.98)[19,20]$. It has moderate concurrent validity (correlation with sit and reach test, $\mathrm{r}=$ 0.57 , correlation with straight leg raise, $r=0.63$ ) [3].

First, the dominant leg is determined as mentioned by O'Hora[21]. Then the participant was placed in the supine position. Hip was flexed to $90^{\circ}$ and maintained at $90^{\circ}$ flexion throughout the test by an examiner of the group. Then the knee is passively extended by another examiner gradually until the maximum tolerable stretch of the hamstring muscle is achieved and the participant himself feeling the maximum stretch of the muscle. The knee extension angle (KEA) is then measured. The second measurement of KEA was made about 6 seconds after the first measurement[3]. During the procedure, contralateral lower extremity was placed on the support surface with knee fully extended and the leg was secured using two cloth straps; one across the thigh and another strap across the anterior superior iliac spine to stabilize the pelvis[22]. The same examiners did the procedure for all the participants and used high quality tools to measure the knee extension angle to reduce the measurement errors.

Figure 1. Measurement procedures for hamstring muscle tightness; $\mathrm{Q}=$ Knee Extension Angle (KEA)

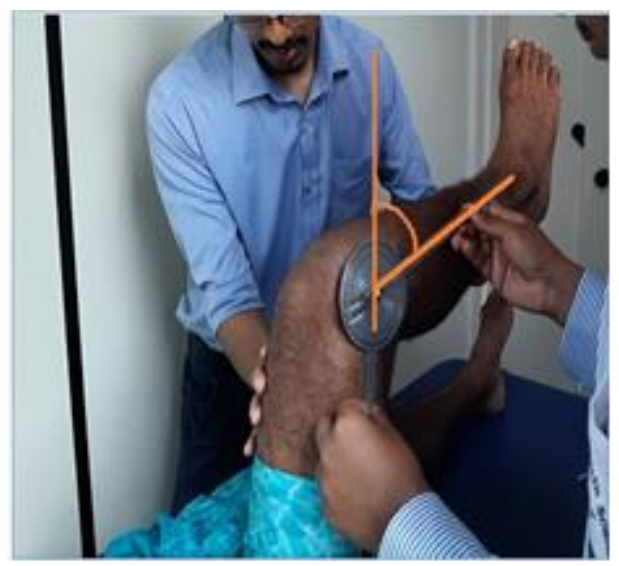

A KEA of $20^{\circ}$ has been defined as a cutoff score indicating hamstring muscle tightness. Therefore, KEA $>20^{\circ}$ indicates hamstring muscle tightness[3].

In the study the height in centimeters $(\mathrm{cm})$ and weight in kilograms $(\mathrm{kg})$ were taken using an electronic digital column scale and put into the standard calculation to obtain the BMI values. The procedure was done according to the standardized protocol which was adapted by the training manual for weight and height assessment by the Arkansas Centre for Health Improvement[23]. BMI was categorized into four groups according to the conventional WHO classification[24].

Statistical Package for Social Sciences (SPSS) version 22.0 software was used for data analysis. Descriptive statistics were used to analyze the characteristics and demographic features of the study sample. To find out the association with hamstring muscle tightness, Chi-Square test at 0.05 significant level was used thus, $\mathrm{P}$ value less than 0.05 was considered as statistically significant. Pearson Correlation test was applied to detect the correlation within the continuous variables. Paired t test was used to compare means of two variables.

\section{Results}

There were 108 females (63.9\%) and 61 males (36.1) in the total of 169 participants. Female to male ratio was 2.6: 1 . The mean age of participants was $30.69 \pm 8.99$ years.

Physical characteristics and occupational characteristics of the sample are given in Table 1.

Majority of them had dominant side, nondominant side hamstring tightness or on both sides. 141 participants had dominant side hamstring tightness (83.4\%) and 125 participants had non dominant side hamstring tightness (73.96\%). Independent $t$ test was carried out to compare the individual's dominant side and nondominant side hamstring tightness. According to the results there was no significant relationship between dominant side and non-dominant side hamstring tightness (Table 2).

The results on the Chi square test on the association between dominant side hamstring muscle tightness and number of sitting hours per day at work are depicted in Table 2. A significant association was observed between the hamstring muscle tightness and number of sitting hours per day at work $(\mathrm{p}=0.02)$. 
Table 1. Physical and occupational characteristics of the sample

\begin{tabular}{|c|c|c|}
\hline & Frequency & $\begin{array}{l}\text { Percent } \\
(\%)\end{array}$ \\
\hline $\begin{array}{l}\text { Dominant side of the } \\
\text { leg }\end{array}$ & & \\
\hline - Right & 115 & 68 \\
\hline - Left & 54 & 32 \\
\hline BMI category & & \\
\hline - Under weight & 40 & 23.7 \\
\hline - Normal weight & 55 & 32.5 \\
\hline - Overweight & 16 & 9.5 \\
\hline - Obese & 58 & 34.3 \\
\hline $\begin{array}{l}\text { Number of sitting } \\
\text { hours }\end{array}$ & & \\
\hline $\begin{array}{l}\text { - } 6 \text { hours chair } \\
\text { sitting per day }\end{array}$ & 64 & 37.9 \\
\hline $\begin{array}{l}\text { - } 7 \text { hours chair } \\
\text { sitting per day }\end{array}$ & 56 & 33.1 \\
\hline $\begin{array}{l}\text { - } 8 \text { hours chair } \\
\text { sitting per day }\end{array}$ & 49 & 29 \\
\hline Physical activity levels & & \\
\hline 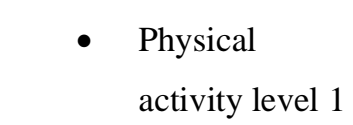 & 12 & 7 \\
\hline $\begin{array}{ll}\text { - } & \text { Physical } \\
& \text { activity level } 2\end{array}$ & 2 & 1 \\
\hline $\begin{array}{ll}\text { - } & \text { Physical } \\
& \text { activity level } 3\end{array}$ & 121 & 72 \\
\hline $\begin{array}{ll}\text { - } & \text { Physical } \\
& \text { activity level } 4\end{array}$ & 28 & 17 \\
\hline $\begin{array}{ll}\text { - } & \text { Physical } \\
& \text { activity level } 5\end{array}$ & 4 & 2 \\
\hline $\begin{array}{ll}\text { - } & \text { Physical } \\
& \text { activity level } 6\end{array}$ & 2 & 1 \\
\hline
\end{tabular}

PAL1; <5000 MET miniweek, PAL2; 5001-10000 MET min/week, PLL3; 10001-1500 MET miniweek, PAL 4;

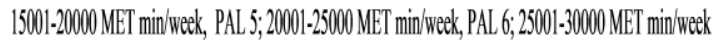

According to Table 2, there is no significant association between dominant side hamstring tightness and BMI. The relationship is shown in Figure 2.

Table 2. Hamstring Muscle Tightness and its associated factors

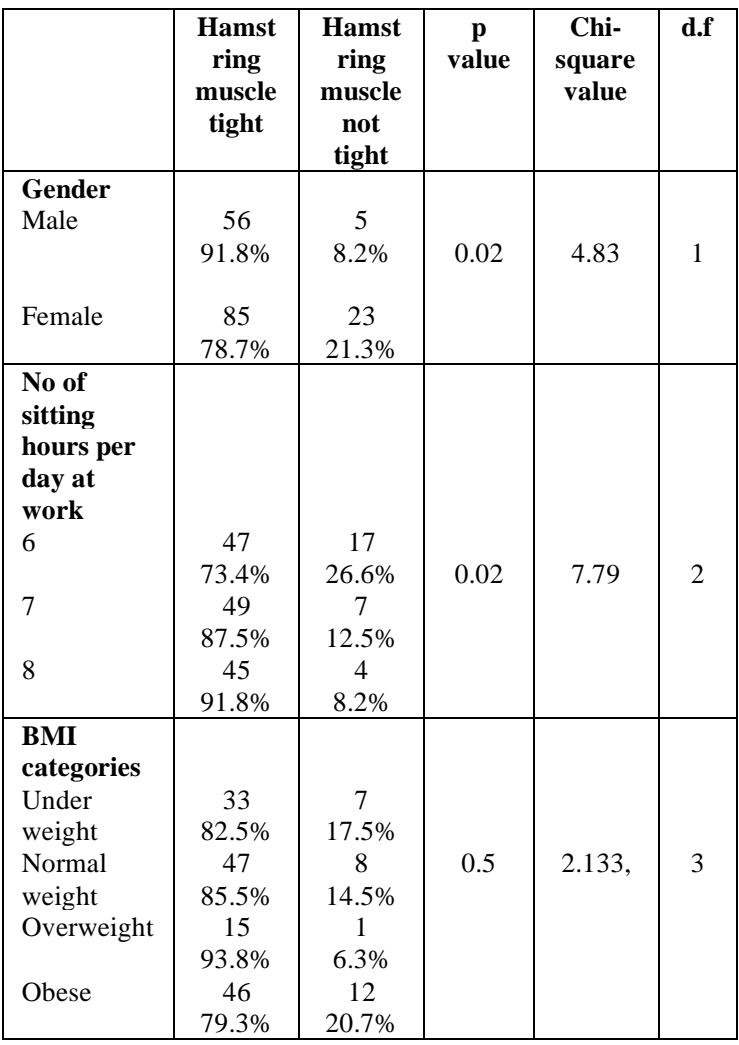

Considering the Pearson correlation test result, no significant correlation was found between dominant side hamstring muscle tightness and PAL ( $p=0.41)$ and the relationship is shown in Figure 3

\section{Discussion}

The results of our study shows relatively a high prevalence of hamstring tightness among sewing machine operators. Several studies conducted among different populations also have shown similar results. A study done among college students have shown $82 \%$ prevalence of hamstring tightness and office workers have shown $85.7 \%$ prevalence $[12,13]$. The similarity may be as a result of selecting the samples from prolonged sitting populations. In contrast to this, a study performed among undergraduate physiotherapy students in Nepal have shown a medium prevalence of hamstring tightness (40.17\%)[14]. This may be due to the physiotherapy students actively participating in 
exercise prescription in stretching. This may also be due to genetic factor[1].

Figure 2. Relationship between hamstring muscle tightness and BMI

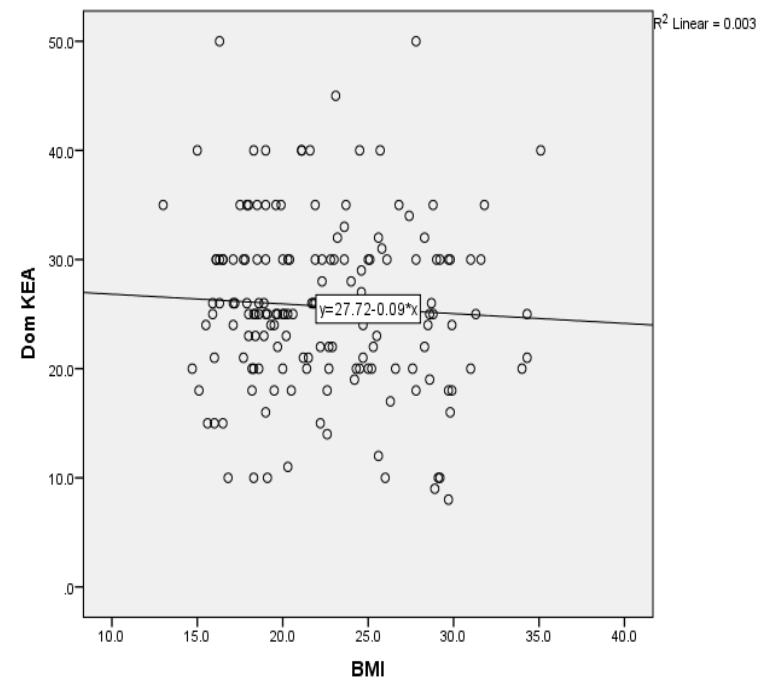

Figure 3: Relationship between hamstring muscle tightness and PAL

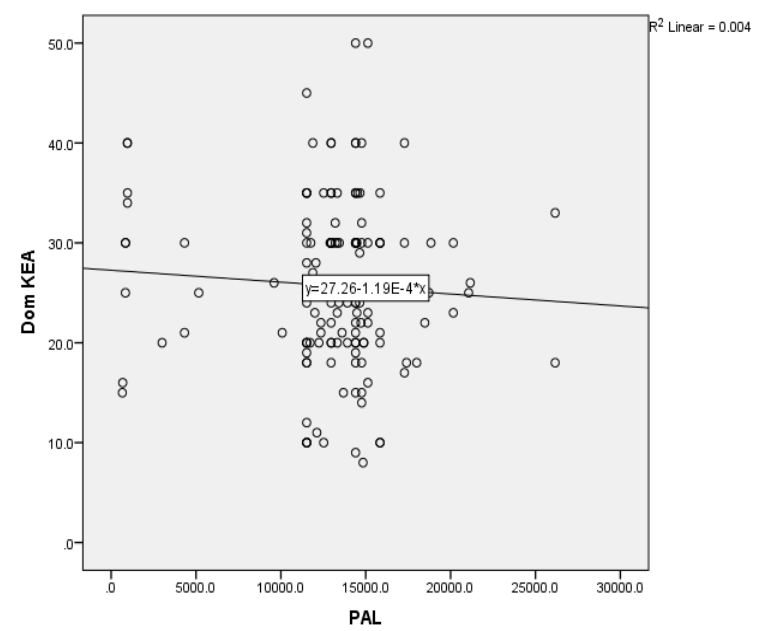

According to the current study, chi square test shows a significant association between the hamstring tightness and number of sitting hours at work $\left(p=0.02, x^{2}=7.79\right)$. Similarly, Fathima states a significant association of hamstring tightness with chair sitting hours $(\mathrm{p}=0.01)$ and Waqas also states a significant positive correlation between hamstring tightness and prolonged sitting $[12,13]$. Adar also states that hamstring shortening increases with sitting hours and has found a significant negative correlation with the straight leg raising test $(r=-0.2794, p=0.0007)$ [9]. In contrast to the above results, Arab states that among all subjects with sitting work setting, $46 \%$ of subjects with LBP and $24 \%$ of normal subjects had hamstring tightness and in subjects with standing work setting, $40 \%$ of subjects with LBP and $16 \%$ of normal subjects had hamstring tightness. He also state that his findings shows work setting (Sitting/Standing) has no effect on hamstring tightness[2].

The current study did not find any significant relationship between dominant side and nondominant side hamstring tightness $(\mathrm{t}=1.94$, $\mathrm{p}=0.05$ ). A study conducted among healthy young people also has shown that there was no significant difference with knee extension angle and dominant limb[25]. Another study conducted among LBP patients have revealed that non dominant side hamstring is tighter than dominant side[10]. However further studies should be done to further assess this difference .Other than that most of the studies showed differences between the range of motion or muscle flexibility of right and left extremities[26-28].

Most of the literature supported the fact that females have greater hamstring muscle flexibility than men[13,14,29]. Furthermore, another study reported that females were found to have significantly greater range of motion than males [30]. Literature state that female tends to be more flexible than the male of same age throughout life. This is because of anatomical variation in joint structure and also performance of more rigorous physical work by men, resulting in greater micro trauma[11].

Although previous studies on influence of BMI on hamstring tightness are limited, there are some studies that show a weak association between hamstring muscle tightness and BMI[31].

In the current study the hamstring tightness was insignificantly associated with PAL $(\mathrm{p}=0.41)$. These results were consistent with the previous study findings[32]. These results contrast a study done to determine the association between BMI and hamstring /back flexibility among the 300 adolescents in Mumbai where physical activity level was shown to be a significant factor for hamstring tightness seen among adolescents irrespective of the BMI value[33].

\section{Conclusion and recommendations}

There is a high prevalence of hamstring muscle tightness $(83.4 \%$ in dominant side and $73.96 \%$ in non-dominant side) among sewing machine operators of the selected garment factory and it is 
higher in male (91.8\%) compared to female (78.7\%). Hamstring tightness is significantly associated with the increase of number of sitting hours. There is no significant association of hamstring tightness with BMI, physical activity level and dominant limb.

Muyor stated that offering physical activity programs at the work place can be an efficient strategy to increase muscle flexibility[34]. For this, static stretching exercise for hamstring can be practiced during the working hours. We recommend effective interventions to improve hamstring tightness at work setting should be assessed in further studies. Further studies with a large number of sewing machine operators will help to generalize the findings.

\section{Acknowledgement}

This research was carried out as a requirement for the final year graduation in BSc. Physiotherapy program. We would like to show our gratitude to the board of management and the staff of the garment factory for their support.

\section{References}

1. Akinpelu AO, Bakare U, Adegoke, BOA. Influence of Age on Hamstring Tightness in Apparently Healthy Nigerians. Journal of the Nigeria Society of Physiotherapy 2005;15(2):35-41.

2. Arab AM, Nourbakhsh MR. Hamstring Muscle Length and Lumbar Lordosis in Subjects with Different Lifestyle and Work Setting: Comparison between Individuals with and without Chronic Low Back Pain. Journal of Back and Musculoskeletal Rehabilitation2014;27(1):63-70. doi.org/ 10.3233/BMR-130420.

3. Davis DS, Quinn RO, Whiteman CT, et al. Concurrent Validity of Four Clinical Tests Used to Measure Hamstring Flexibility. Journal of Strength and Conditioning Research2008;22(2):583-588. doi.org/10.1519/JSC.0b013e31816359f2

4. Phansopkar PA and Kage V.'Efficacy of Mulligan'S Two Leg Rotation and Bent Leg Raise Techniques in Hamstring Flexibility in Subjects With Acute NonSpecific Low Back Pain: Randomized Clinical Trial'. International Journal of Physiotherapy and Research 2014;2(5):733-41.

5. Radwan A, Bigney KA, Buonomo HN, et al. Evaluation of Intra-Subject Difference In Hamstring Flexibility In Patients With Low Back Pain: An Exploratory Study.
Journal of Back and Musculoskeletal Rehabilitation 2015;28(1):61-6 doi.org/ 10.3233/BMR-140490

6. Labovitz JM, Yu J, Kim C. The Role of Hamstring Tightness in Plantar Fasciitis. Foot \& Ankle Specialist 2011;4(3):141144. doi.org/ 10.1177/1938640010397341

7. Export Development Board, Sri Lanka. Sri Lankan Apparel Sector, Industry Capability Report 2016;1-9.

8. Lombardo SR, Silva VD, Lipscomb HJ, et al. Musculoskeletal Symptoms among Female Garment Factory Workers in Sri Lanka. International Journal of Occupational and Environmental Health 2012;18(3):210-219.

doi.org/ 10.1179/1077352512Z.00000000 029

9. Adar BZ. Risk factors of prolonged sitting and lack of physical activity in relate to postural deformities, muscles tension and backache among Israeli children. A clinical cross sectional research, ProQuest Dissertations and Theses 2004;156-156.

10. Reis FJJ and Macedo AR.'Influence of hamstring tightness in pelvic, lumbar and trunk range of motion in low back pain and asymptomatic volunteers during forward bending'. Asian Spine Journal 2015;9(4):535-540. doi.org/ 10.4184/asj.2015.9.4.535

11. Mistry G, Vyas N, Sheth M. Correlation of hamstrings flexibility with age and gender in subjects having chronic low back pain. International Journal of Therapies and Rehabilitation Research 2014;3(4):3138.doi.org/ 10.5455/ijtrr.00000040

12. Fatima G, Qamar MM, Ul Hassan J, et al. Extended sitting can cause hamstring tightness. Saudi Journal of Sports Medicine 2017;17(2):110-114. doi.org/ 10.4103/sjsm.sjsm_5_17

13. Waqas MS, Naqvi SMA, Hussain HS, et al. Frequency of Reduced Hamstring Flexibility in Prolong Sitting (6-8 Hours) Among Office Workers. Journal of Riphah College of Rehabilitation Sciences 2016;4(2):77-80.

14. Shakya NR and Manandhar S. Prevalence of Hamstring muscle tightness among undergraduate physiotherapy students of Nepal using Passive Knee Extension Angle Test. International Journal of Science and Research Publications 2018;8(1):182.

15. Weerasekara I, Kumari I, Weerarathna N, et al. The Prevalence of Hamstring Tightness among the Male Athletes of University of Peradeniya in 2010, Sri Lanka. International Journal of Physical 
Medicine \& Rehabilitation 2013;1(1):5658.doi.org/ 10.4172/2329-9096.1000108

16. World Health Organization (2018): Physical Activity. [online] Available at: http://www.who.int/dietphysicalactivity/pa /en/ [Accessed 25 Mar. 2018].

17. Bull FC, Maslin TS, Amstrong T. Global Physical Activity Questionnaire (GPAQ): nine country reliability and validity study. Journal of physical act health 2009;6(6):790-804.

18. Thuy AB, Blizzard L, Schmidt M, et al. Reliability and validity of the global physical activity questionnaire in Vietnam. Journal of Physical Activity \& Health 2010;7(3):410-418.

19. Guex K, Fourchet F, Loepelt H, er al. 'Passive Knee-Extension Test to Measure Hamstring Tightness: Influence of Gravity Correction'. Journal of Sport Rehabilitation 2011;21(3):231-234. doi.org/ 10.1123/jsr.21.3.231

20. Fredriksen H, Dagfinrud H, Jacobsen V, et al. Passive knee extension test to measure hamstring muscle tightness. Scandinavian Journal of Medicine \& Science in Sports 1997;7(5): 279-282.

21. O'Hora J, Cartwright A, Wade CD, et al. Efficacy of Static Stretching and Proprioceptive Neuromuscular Facilitation Stretch on Hamstrings Length after a Single Session. Journal of Strength and Conditioning Research 2011;25(6):15861591. doi.org/ 10.1519/JSC.0b013e3181df7f98

22. Gajdosik RL, Hatcher CK, Whitsell S. Influence of short hamstring muscles on the pelvis and lumbar spine in standing and during the toe-touch test. Clinical Biomechanics Elsevier 1992;7(1):38-42. doi.org/10.1016/0268-0033(92)90006-P.

23. http://www.achi.net/BMIContent/Docume nts/101007_Height_and_Weight_Measure ment_Training_Manual1with_revisions.pd f (accessed 6 January 2019)

24. Executive summary of the clinical guidelines on the identification, evaluation, and treatment of overweight and obesity in adults. Arch Intern Med. 1998;158(17):1855-1867. doi.org/10.1001/archinte.158.17.1855

25. Yildirim SM, Tuna F, Kabayel DD, et al. The Cut-off Values for the Diagnosis of
Hamstring Shortness and Related Factors. Balkan Med J. 2018;35(5):388-393. doi.org/ 10.4274/balkanmedj.2017.1517

26. Ahlberg A, Moussa M, Al-Nahdi M. On geographical variations in the normal range of joint motion. Clin Orthop Relat Res. 1998;234:229-231.

doi.org/10.1097/00003086-19880900000040

27. Roaas A and Andersson GBJ. Normal range of motion of the hip, knee and ankle joints in male subjects, 30-40 years of age. Acta Orthop Scand. 1982;53:205-208. doi.org/10.3109/17453678208992202

28. Stefanyshyn DJ and Engsberg JR. Right to left differences in the ankle joint complex range of motion. Med Sci Sports Exer. 1994;26:551-555. doi.org/10.1016/0021-9290(94)91377-3

29. Youdas JW, Krause DA, Hollman JH, et al. Influence of gender and age on hamstring muscle length in healthy adults. Journal of Orthopaedic and Sports Physical Therapy 2005;35(4):246-252.

doi.org/10.2519/jospt.2005.35.4.246

30. Allander E, Bjornsson OJ, Olafsson O, et al. Normal Range of Joint Movements in Shoulder, Hip, Wrist and Thumb with Special Reference to Side: A Comparison between Two Populations. International Journal of Epidemiology 1974);3(3):253261. doi.org/10.1093/ HYPERLINK "https://doi.org/10.1093/ije/3.3.253"ije HYPERLINK "https://doi.org/10.1093/ije/3.3.253"/3.3.2 53

31. Shah S and Vanwala J. Correlation of body mass index and health related physical fitness in young healthy individuals. Indian journal of physical therapy 2015;3(2):1-4.

32. Graciosa MD. Effect of sedentary lifestyle, nutritional status and sex on the flexibility of students Effect of Sedentary Lifestyle, Nutritional Status and Sex. Journal of Human Growth and Development 2013;23(2):144-150.

33. Arora A, Souza SD, Yardi S. Association between Body Mass Index and Hamstring / Back Flexibility in Adolescent Subjects. International Journal of Science and Research 2015;5(7):2013-2016. ISSN (Online): 2319-706 